\title{
Randomised controlled trial of effects of coordinating care for terminally ill cancer patients
}

\author{
J M Addington-Hall, L D MacDonald, H R Anderson, J Chamberlain, P Freeling, J M Bland, \\ J Raftery
}

Department of Public

Health Sciences, St

George's Hospital Medical

School, University of

London, London

SW17 0RE

J M Addington-Hall, research fellow

L D MacDonald, senior

lecturer in medical sociology

H R Anderson, professor

$\mathrm{J} M$ Bland, senior lecturer in

medical statistics

$\mathrm{J}$ Raftery, health economist

South West Thames

Regional Cancer

Organisation, Royal

Marsden Hospital, Sutton,

Surrey SM2 5PT

J Chamberlain, regional

specialist in cancer services

Division of General

Practice and Primary Care,

St George's Hospital

Medical School

P Freeling, professor

Correspondence to:

Dr J M Addington-Hall, Department of

Epidemiology and Public

Health, University College

London, 66-72 Gower

Street, London WC1E 6EA.

BMF 1992;305:1317-22

\begin{abstract}
Objectives-To measure effects on terminally ill cancer patients and their families of coordinating the services available within the NHS and from local authorities and the voluntary sector.

Design-Randomised controlled trial.

Setting-Inner London health district.

Patients-Cancer patients were routinely notified from 1987 to 19.90 .554 patients expected to survive less than one year entered the trial and were randomly allocated to a coordination or a control group.
\end{abstract}

Intervention-All patients received routinely available services. Coordination group patients received the assistance of two nurse coordinators, whose role was to ensure that patients received appropriate and well coordinated services, tailored to their individual needs and circumstances.

Main outcome measures-Patients and carers were interviewed at home on entry to the trial and at intervals until death. Interviews after bereavement were also conducted. Outcome measures included the presence and severity of physical symptoms, psychiatric morbidity, use of and satisfaction with services, and carers' problems. Results from the baseline interview, the interview closest to death, and the interview after bereavement were analysed.

Results-Few differences between groups were significant. Coordination group patients were less likely to suffer from vomiting, were more likely to report effective treatment for it, and less likely to be concerned about having an itchy skin. Their carers were more likely to report that in the last week of life the patient had had a cough and had had effective treatment for constipation, and they were less likely to rate the patient's difficulty swallowing as severe or to report effective treatment for anxiety. Coordination group patients were more likely to have seen a chiropodist and their carers were more likely to contact a specialist nurse in a night time emergency. These carers were less likely to feel angry about the death of the patient.

Conclusions-This coordinating service made little difference to patient or family outcomes, perhaps because the service did not have a budget with which it could obtain services or because the professional skills of the nurse-coordinators may have conflicted with the requirements of the coordinating role.

\section{Introduction}

Although some terminally ill cancer patients and their families receive prompt and adequate services, others have unmet need for control of symptoms, help to relieve psychological distress, more information from doctors and nurses, and appropriate practical help..$^{1-3}$ Such findings have been reported for more than 20 years $^{45}$ despite the rapid development of specialist hospice services, ${ }^{6-8}$ and there is clearly no room for complacency about the provision of services for these patients.

Inadequate care can result from a lack of specialist knowledge and skills. This is being dealt with by the continuing growth of the hospice movement ${ }^{9}$ and the increasing emphasis on training doctors and nurses in palliative care. ${ }^{10}$ However, poor care may also arise from a lack of coordination and planning between the numerous health, local authority, and voluntary sector services that provide care for these patients. This may result in the duplication of services to some, while others do not receive help because each agency assumes that another is dealing with the problem.

Wandsworth Health Authority, an inner London health district, employed two nurse coordinators as an experiment from April 1987 to June 1990. Their role was to ensure that all terminally ill cancer patients received appropriate, adequate, and well coordinated services, tailored to their changing needs and circumstances. The service was evaluated independently by a randomised controlled trial. The effects on patient and family outcomes are presented here. The cost effectiveness of the service will be reported separately.

\section{Methods}

INTERVENTION

Initially, two experienced district nurses who held the English National Board for Nursing, Midwifery and Health Visiting (ENB) certificate of care of the dying patient were recruited as coordinators. One coordinator left during the trial and was replaced first by a health visitor and later by another district nurse, neither of whom held the ENB certificate.

The coordinators were community based and introduced themselves to patients as nurses who provided a link between the hospital, the general practitioner, and community services. They acted as "brokers" of services and their role was to assess need for services from agencies in the NHS, local authority, and voluntary sector; to offer advice on how to obtain these services and to contact the agencies themselves if necessary; to ensure that services were provided and were well coordinated; and to stay in regular contact to monitor the changing needs of the patient and family for services. Patients were encouraged to contact the coordinators if they needed help or advice. The coordinators did not themselves provide practical nursing care, specialist palliative care advice, or counselling; instead they liaised with district nurses and hospice or Macmillan nurses, as appropriate, when patients required this type of support.

The coordinators were in post for one year before the evaluation began, using this time to develop their 
assessment procedures, familiarise themselves with available services, and develop the necessary cooperative relationships with other professionals.

\section{PATIENTS AND ALLOCATION}

To prevent the contamination that could occur if patients of the same general practice had been allocated to different groups, general practices in the district were randomly allocated to the coordination or the control group, stratified by number of partners and postal district. Initially 89 practices were allocated to the coordination group and 79 to the control group. By September 1987 it was apparent that too few patients were entering the coordination group to keep the nurse coordinators fully employed. Thirteen randomly selected control group practices were therefore transferred to the coordination group. This change in randomisation has been allowed for in the analysis. Because there were very few patients from each practice and the intervention was directly to the patient, the practice was ignored in the analysis.

Each time a cancer patient was admitted to a Wandsworth district hospital or attended oncology, radiotherapy, general surgery, or urology outpatient clinics, the research team was notified and the doctor or senior nurse assessed the patient as having a prognosis of more or less than one year. Patients expected to live for less than a year and who were resident within the boundaries of the health authority entered the trial and were allocated to coordination or control group depending on the general practice with which they were registered. All recruited patients continued to receive routinely available services. Those allocated to the coordination group also received the services of nurse coordinators.

\section{EVALUATION}

Independent interviewers, who were not informed which group the patients were in, interviewed patients at home on entry to the trial (baseline interview) and at intervals ranging from two weeks to six months until death or the end of the trial (follow up interviews). The interval varied according to the severity of the patient's condition, as assessed by the Spitzer quality of life index," scores on which have been shown to be correlated with survival. ${ }^{12}$ At baseline interview patients designated their principal carer. Carers were interviewed at follow up interviews and again eight weeks after bereavement.

At each interview information was collected on symptoms and symptom control, drugs, activities of daily living, and sources of help; satisfaction with services; psychological distress as measured by the hospital anxiety and depression scale $^{13}$; and a short validated measure of social support, the family Apgar scale ${ }^{14}$ which has values from 0 to 10,0 indicating absence of support. The interviewers completed the Spitzer quality of life index after each interview. Values on this also range from 0 to 10,0 indicating poor quality of life.

In addition, at each follow up interview patients were asked about service use and sources of income. Carers were asked about the experience and problems of caring and about their satisfaction with services and completed the Leeds depression and anxiety scale. ${ }^{15} \mathrm{At}$ interview after bereavement information was collected on the patient's symptoms in the last week of life, the carers' own health and adjustment since bereavement, and their satisfaction with services.

Initially it was expected that 400 patients would be recruited to the trial. Half were expected to have follow up interviews, making it possible to show that $60 \%$ in one group differed significantly at the $5 \%$ level from $40 \%$ in the other group, with a power of $80 \%$. If only half the expected number had follow up interviews the sample size would be sufficient to show that $70 \%$ differed significantly from $40 \%$, again with a power of $80 \%$ and significance level $5 \%$.

Information from the interview nearest death (or nearest the end of the study, for patients alive at this point) and from the interview after bereavement were used to measure the effects of the coordinating service on patients and families. Scores at the baseline interview were controlled for with the Mantel-Haenszel test for categorical data ${ }^{10}$ and regression analyses for interval data. The Mantel-Haenszel test was also used to control for the effects of the change in randomisation. Differences between groups on variables where the number of cases was too small for control variables to be taken into account were tested with the $\chi^{2}$ statistic. Survival times were calculated with the Kaplan-Meier method and the change in randomisation was controlled for with Cox's regression analysis. ${ }^{1}$

Odds ratios adjusted for the randomisation change and baseline scores (where appropriate) are presented, except where an adjusted odds ratio could not be calculated because subgroups contained zeros, in which cases unadjusted odds ratio are presented. Combined $\chi^{2}$ values derived from the Mantel-Haenszel statistic and controlled for the randomisation change and baseline scores are presented unless otherwise specified.

\section{Results}

A total of 554 patients entered the trial, of whom 194 $(35 \%)$ died or were too ill to be interviewed, $40(7 \%)$ moved away, and $39(7 \%)$ declined to be interviewed (figure); 281 patients $(51 \%)$ received a baseline interview, 203 of whom $(72 \%)$ had at least one follow up interview, 104 in the coordination group and 99 in the control group. Data from these patients are included in the analyses reported in this paper.

In all, 69 patients $(34 \%)$ had no informal carers living locally, seven $(4 \%)$ did not wish their carers to be interviewed, and nine carers $(5 \%)$ did not wish to be interviewed. A total of 118 carers $(58 \%)$ were interviewed at least once, 56 carers of coordination group patients and 62 carers of control group patients. One hundred and fifteen patients whose carers were interviewed had died by the end of the study; 18 carers declined to be interviewed after bereavement, and

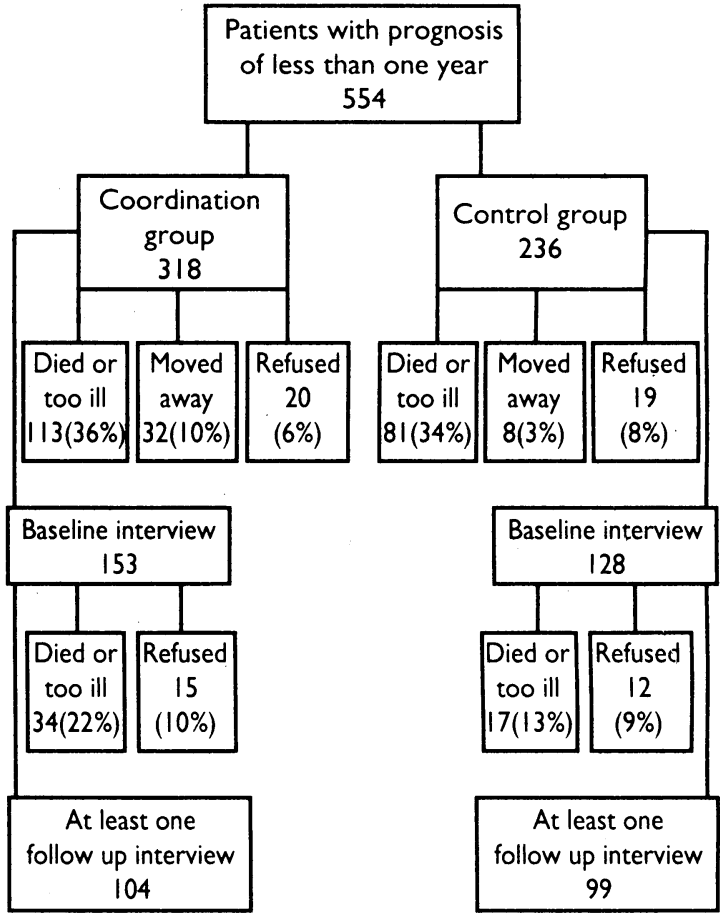

Outcome for 554 patients who entered trial 
three had moved away. Thus 94 carers were interviewed about eight weeks after the death of the patient, 51 carers of coordination group patients and 43 carers of control group patients.

\section{PATIENT AND CARER CHARACTERISTICS}

Table I shows characteristics and primary cancer site of patients. Carers' characteristics did not differ significantly between groups. Overall, $84 \%$ lived with and $65 \%$ were married to the patient, and $30 \%$ of carers were male.

\section{TIME TO DEATH}

The time between final follow up interview and death did not differ significantly between groups (table II). Control group patients were more likely to have died by the end of the study (adjusted odds ratio $=1.90$ (95\% confidence interval 1.01 to 3.58 ), combined $\chi^{2}=3 \cdot 6, \mathrm{df}=1, \mathrm{p}=0 \cdot 06$ ), especially patients recruited before the randomisation change (35/42 $v 13 / 22$, odds ratio $=3.5(1.1$ to 11.2$\left.), \chi^{2}=4.5, \mathrm{df}=1, \mathrm{p}=0.03\right)$; this was less evident in those recruited later in the trial $\left(42 / 57 v 56 / 82\right.$, odds ratio $=1.42(0.7$ to 3.0$), \chi^{2}=0 \cdot 84$, $\mathrm{df}=1, \mathrm{p}>0.05)$. The difference between groups in the length of survival after entry to the trial as assessed by the Cox regression procedure was just significant $(p=0.05)$.

\section{EXPERIENCES OF PATIENTS}

Patients in the coordination group were significantly less likely to have been suffering from vomiting (combined $x^{2}=3 \cdot 69, \mathrm{df}=1, \mathrm{p}=0.05$ ), but there were no other significant differences in the symptoms experienced in the 24 hours before interview (table III). There were also few statistically significant differences in severity of symptoms, concern about symptoms, and effectiveness of treatment: coordination group patients were more likely to be receiving effective treatment for vomiting ( $3 / 4 \vee 1 / 9$, unadjusted odds ratio $=0.04(0.02$ to 0.79$)$, combined $\chi^{2}=5 \cdot 79, \mathrm{df}=1$, $p=0.02)$ and were less likely to be concerned about having an itchy skin $(6 / 27 v 16 / 30$, odds ratio adjusted for randomisation change $=3.7(1.12$ to $12 \cdot 1)$, combined $\chi^{2}=5 \cdot 42, \mathrm{df}=1, \mathrm{p}=0 \cdot 02$ ). There were no group differences in the type of analgesics taken, nor in the

TABLE I-Characteristics of patients. Values are numbers of patients

\begin{tabular}{|c|c|c|}
\hline & $\begin{array}{l}\text { Study group } \\
(\mathrm{n}=104)\end{array}$ & $\begin{array}{c}\text { Control group } \\
(\mathrm{n}=99)\end{array}$ \\
\hline \multicolumn{3}{|l|}{ Age: } \\
\hline $18-49$ & 3 & 5 \\
\hline $50-64$ & 16 & 19 \\
\hline $65-74$ & 32 & 21 \\
\hline$\geqslant 75$ & 53 & 54 \\
\hline \multicolumn{3}{|l|}{ Marital status: } \\
\hline Single & 16 & 9 \\
\hline Widowed & 33 & 29 \\
\hline Divorced & 7 & 6 \\
\hline Married & 48 & 55 \\
\hline Men & 48 & 46 \\
\hline Living alone & 42 & 33 \\
\hline All male household & 15 & 10 \\
\hline All members of household over age of 64 & 64 & 52 \\
\hline Owner-occupier & 37 & 35 \\
\hline Non-manual occupation & 35 & 27 \\
\hline \multicolumn{3}{|l|}{ Relatives living in: } \\
\hline Same road & 9 & 13 \\
\hline Same neighbourhood & 25 & 34 \\
\hline One hour's driving distance & 73 & 65 \\
\hline Elsewhere in UK & 70 & 65 \\
\hline \multicolumn{3}{|l|}{ Contact once a week or more: } \\
\hline With relatives & 58 & 55 \\
\hline With friends & 71 & 73 \\
\hline \multicolumn{3}{|l|}{ Primary cancer: } \\
\hline Breast & 16 & 14 \\
\hline Lung & 19 & 22 \\
\hline Colorectal & 20 & 19 \\
\hline Prostate & 15 & 9 \\
\hline Other & 34 & 35 \\
\hline \multirow{2}{*}{$\begin{array}{l}\text { Household weekly income (after tax) } \\
\text { of under } £ 100^{\star}\end{array}$} & & \\
\hline & 57 & 53 \\
\hline
\end{tabular}

* Study group, $n=82$; control group, $n=80 ; 19$ patients refused to answer question, 23 did not know household income.
TABLE II-Time to death. Values are numbers of patients

\begin{tabular}{lcc}
\hline & $\begin{array}{c}\text { Study group } \\
(\mathrm{n}=104)\end{array}$ & $\begin{array}{c}\text { Control group } \\
(\mathrm{n}=99)\end{array}$ \\
\hline $\begin{array}{l}\text { Weeks between final follow up interview } \\
\text { and death: } \\
\leqslant 4\end{array}$ & & \\
$5-8$ & 18 & 13 \\
$9-12$ & 15 & 15 \\
$13-24$ & 11 & 14 \\
$25-52$ & 15 & 17 \\
$\geqslant 52$ & 4 & 15 \\
Dead before end of study & 3 & 3 \\
Median survival (days) $\dagger$ & 66 & 77 \\
& 385 & 340 \\
\hline
\end{tabular}

${ }^{\star} \mathrm{n}=66$ in study group, 77 in control group.

†Kaplan-Meier method

TABLE III-Symptoms experienced in 24 hours before interview. Values are numbers of patients

\begin{tabular}{|c|c|c|c|}
\hline & \multicolumn{2}{|c|}{ Symptom present } & \multirow[b]{2}{*}{$\begin{array}{l}\text { Adjusted odds ratio } \\
\text { (95\% confidence } \\
\text { interval })^{\star}\end{array}$} \\
\hline & $\begin{array}{l}\text { Study } \\
\text { group } \\
(n=104)\end{array}$ & $\begin{array}{l}\text { Control } \\
\text { group } \\
(\mathrm{n}=99)\end{array}$ & \\
\hline Pain & 55 & 56 & $0.90(0.50$ to 1.64$)$ \\
\hline Loss of appetite & 54 & 49 & $1.23(0.70$ to 2.17$) \dagger$ \\
\hline Difficulty swallowing & 9 & 14 & $0.65(0.27$ to 1.59$) \dagger$ \\
\hline Vomiting & 4 & 11 & $0.24(0.07$ to 0.77$) t$ \\
\hline Nausea & 20 & 19 & $1.12(0.55$ to 2.27$)$ \\
\hline Breathlessness & 61 & 61 & $0.93(0.49$ to 1.78$)$ \\
\hline Cough & 36 & 37 & $0.88(0.48$ to 1.64$)$ \\
\hline Itchy skin & 27 & 30 & $0.81(0.43$ to 1.54$)$ \\
\hline Constipation & 31 & 36 & $0.98(0.53$ to 1.80$)$ \\
\hline Diarrhoea & 10 & 6 & $1.54(0.48$ to 5.00$) t$ \\
\hline Incontinence or retention & 15 & 21 & $0.56(0.25$ to 1.25$)$ \\
\hline Sleeplessness & 35 & 37 & $0.81(0.45$ to 1.49$)$ \\
\hline Depression & 50 & 56 & $0.95(0.50$ to 1.80$)$ \\
\hline Anxiety & 32 & 43 & $0.73(0.40$ to 1.35$)$ \\
\hline
\end{tabular}

* Adjusted for baseline scores and change in randomisation

†Adjusted for randomisation change only, owing to small numbers.

proportions of patients taking antiemetics, laxatives, antidepressant drugs, sedatives, or anxiolytics.

There were few between group differences in the carers' reports of the type, severity, and effectiveness of treatment of the patient's symptoms in the last week of life: carers of coordination group patients were more likely to report that the patient had had a cough $(21 / 50$ $v 8 / 39$, adjusted odds ratio $=0.32(0.12$ to 0.83$)$, combined $\left.\chi^{2}=4 \cdot 37, \mathrm{df}=1, \mathrm{p}=0 \cdot 04\right)$, less likely to rate the patient's difficulty with swallowing as severe $(7 / 20$ $v 13 / 17$, unadjusted odds ratio $=6.04(1.42$ to $25 \cdot 7)$, combined $\chi^{2}=4 \cdot 27, \mathrm{df}=1, \mathrm{p}=0 \cdot 03$ ), more likely to report effective treatment for constipation $(18 / 33 v$ $4 / 23$, adjusted odds ratio $=0.14(0.04$ to 0.51$)$, combined $x^{2}=7 \cdot 1, \mathrm{df}=1, \mathrm{p}=0 \cdot 01$ ), and less likely to report effective treatment for anxiety $(0 / 16 v 3 / 10$, combined $\chi^{2}=6 \cdot 7, d f=1, p=0 \cdot 01$ ).

The proportion of patients with scores above 10 on the hospital anxiety and depression scales, the suggested cut off point for symptoms severe enough to warrant psychiatric treatment, did not differ significantly between groups (table IV). Overall, patients had a mean score of 5.3 (SD 1.7) on the Spitzer quality of life index, and $30 \%$ had scores on the family Apgar scale of 6 or below, indicative of low social support. The groups did not differ significantly on these measures.

A total of $159(78 \%)$ patients needed help with one or more self care activities, $86(42 \%)$ required nursing care, and $61(30 \%)$ required assistance during the night. A total of $159(78 \%)$ needed help with errands outside the home and $168(83 \%)$ needed help with routine household tasks. The two groups were equally likely to need help. There were no group differences in sources of help (informal carers, district nurses, or home helps), in the proportions having unmet needs for help, or in the proportions who had aids and appliances for use at home.

According to carers, 42 (45\%) patients had been unable to eat, wash, use the toilet, and dress, even with help, during the last week of life. Fifty $(54 \%)$ had been 
bed bound and eight $(9 \%)$ had been unable to communicate. Again, the two groups were not significantly different in these respects.

\section{FINANCE AND BENEFITS}

A total of 187 patients $(92 \%)$ answered questions on financial matters-43 (23\%) had been given some advice on their benefit entitlements and $23(12 \%)$ were receiving attendance allowance. Thirty eight per cent of patients with savings (54) had had to spend some savings since they were last hospitalised. There were no significant differences between groups.

SERVICE USE AND SATISFACTION

The two groups were equally likely to report having had contact with social service agencies, community nursing services, and general practitioners (table V). However, more patients in the coordination group

TABLE IV-Psychological state of patients and carers. Values are numbers (percentages) with scores above cut off for psychological morbidity

\begin{tabular}{|c|c|c|c|}
\hline & $\begin{array}{l}\text { Study } \\
\text { group }\end{array}$ & $\begin{array}{l}\text { Control } \\
\text { group }\end{array}$ & $\begin{array}{l}\text { Adjusted odds ratio } \\
\text { (95\% confidence } \\
\text { interval) }\end{array}$ \\
\hline \multicolumn{4}{|c|}{ Patients (hospital anxiety and depression scale): } \\
\hline Depression scale & $17(20)$ & $28(36)$ & $0.55(0.26$ to 1.15$) \ddagger$ \\
\hline Anxiety scale & $12(14)$ & $20(26)$ & $0.52(0.23$ to 1.15$) \ddagger$ \\
\hline \multicolumn{4}{|c|}{ Carers (Leeds anxiety and depression scale): $\dagger$} \\
\hline \multicolumn{4}{|c|}{ Before death of patient: $\S$} \\
\hline Depression scale & $21(38)$ & $25(40)$ & $0.77(0.36$ to 1.64$)$ \\
\hline Anxiety scale & $22(39)$ & $32(52)$ & $0.65(0.31$ to 1.37$) \|$ \\
\hline \multicolumn{4}{|l|}{ After bereavement: $\mathbb{I}$} \\
\hline Depression scale & $20(39)$ & $19(48)$ & $0.63(0.27$ to 1.47$) \|$ \\
\hline Anxiety scale & $10(20)$ & $13(33)$ & $0.51(0.19 \text { to } 1.31)^{\star \star}$ \\
\hline \multirow{2}{*}{\multicolumn{4}{|c|}{ 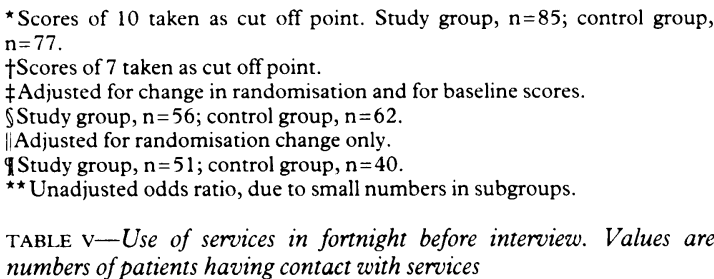 }} \\
\hline & & & \\
\hline & $\begin{array}{l}\text { Study } \\
\text { group } \\
(n=103)\end{array}$ & $\begin{array}{l}\text { Control } \\
\text { group } \\
(\mathrm{n}=99)\end{array}$ & $\begin{array}{l}\text { Adjusted odds ratio } \\
(95 \% \text { confidence } \\
\text { interval })^{\star}\end{array}$ \\
\hline Home helps & 41 & 43 & $0.84(0.47$ to 1.47$)$ \\
\hline Meals on wheels & 15 & 18 & $0.63(0.28$ to 1.41$)$ \\
\hline Social worker & 7 & 12 & $0.47(0.18$ to $1 \cdot 23)$ \\
\hline Occupational therapist & 6 & 3 & $2.38(0.47$ to $11 \cdot 1)$ \\
\hline Physiotherapist & 3 & 2 & $1.45(0.23$ to 9.09$) \dagger$ \\
\hline Chiropodist & 7 & 1 & $7.14(0.85$ to 50.0$) t$ \\
\hline Special laundry services & 2 & 3 & $1.61(0.10$ to 3.85$) t$ \\
\hline District nurses & 38 & 39 & $0.84(0.47$ to 1.49$)$ \\
\hline Oncology sister & 14 & 13 & $0.91(0.38$ to $2 \cdot 13)$ \\
\hline \multicolumn{4}{|l|}{ Hospice or Macmillan } \\
\hline & 7 & 11 & $0.44(0.16$ to $1 \cdot 19)$ \\
\hline \multicolumn{4}{|l|}{ General practitioner: } \\
\hline Home visit & 23 & 23 & $1.01(0.52$ to 1.92$)$ \\
\hline Surgery consultation & 13 & 18 & $0.70(0.32$ to 1.54$)$ \\
\hline
\end{tabular}

*Adjusted for change in randomisation.

tUnadjusted owing to small numbers in subgroups.

TABLE VI-Satisfaction of patients and carers with hospital, general practitioner, and district nurse services and with information from health professionals

\begin{tabular}{|c|c|c|c|c|c|}
\hline & \multicolumn{2}{|c|}{ No able to comment } & \multicolumn{2}{|c|}{ No $(\%)$ satisfied } & \multirow{2}{*}{$\begin{array}{l}\text { Adjusted odds ratio } \\
\text { (95\% confidence } \\
\text { interval) }\end{array}$} \\
\hline & $\begin{array}{l}\text { Study } \\
\text { group }\end{array}$ & $\begin{array}{l}\text { Control } \\
\text { group }\end{array}$ & $\begin{array}{l}\text { Study } \\
\text { group }\end{array}$ & $\begin{array}{l}\text { Control } \\
\text { group }\end{array}$ & \\
\hline \multicolumn{6}{|l|}{ Care from hospitals: } \\
\hline Patients & 99 & 86 & $62(63)$ & $45(52)$ & $1.49(0.79 \text { to } 2.77)^{\star}$ \\
\hline Carers & 54 & 58 & $42(78)$ & $40(69)$ & $1.69(0.72$ to 4.0$) t$ \\
\hline \multicolumn{6}{|l|}{ Care from GPs: } \\
\hline Patients & 92 & 81 & $72(78)$ & $63(78)$ & $0.96(0.43 \text { to } 2.17)^{\star}$ \\
\hline Carers & 50 & 55 & $38(76)$ & $42(67)$ & $1.54(0.65$ to 3.70$) \neq$ \\
\hline \multicolumn{6}{|l|}{ Care from district nurses: } \\
\hline Patients & 68 & 42 & $63(92)$ & $40(95)$ & $0.51(0.09$ to 2.70$) \ddagger$ \\
\hline Carers & 37 & 29 & $33(89)$ & $27(93)$ & $0.61(0.10$ to 3.57$) \ddagger$ \\
\hline \multicolumn{6}{|c|}{ Information from hospitals or GPs, or both: } \\
\hline Patients & 99 & 91 & $70(70)$ & $61(67)$ & $1.30(0.66 \text { to } 2.5)^{\star}$ \\
\hline Carers & 57 & 61 & $36(63)$ & $44(72)$ & $0.77(0.35$ to 1.72$) \dagger$ \\
\hline Service from home helps & 41 & 43 & $35(85)$ & $31(72)$ & $2.17(0.73$ to 6.25$) \dagger$ \\
\hline Service from meals on wheels & 13 & 18 & $7(54)$ & $7(39)$ & $3.33(0.78$ to 14.3$) \dagger$ \\
\hline
\end{tabular}

* Adjusted for change in randomisation and for baseline scores.

tAdjusted for randomisation change only.

$\ddagger$ Unadjusted. reported contact with a chiropodist in the two weeks before interview (combined $\chi^{2}$ (controlling for randomisation change $)=6.05, \mathrm{df}=1, \mathrm{p}<0.02)$. Frequency of contact with these agencies and satisfaction with services (table VI) did not differ significantly between groups.

Fifty three $(45 \%)$ carers contacted their general practitioner if they wanted help or advice, $25(21 \%)$ contacted a hospital ward or the patient's consultant, nine $(8 \%)$ a district nurse, and $11(9 \%)$ a specialist nurse (Macmillan nurse, oncology sister, or coordinator). If the patient needed help urgently out of hours, a third of carers (39) contacted the ambulance service, $27 \%(31)$ the general practitioner, and $14 \%$ (17) the hospital ward or consultant. Carers of coordination group patients were significantly more likely to contact a Macmillan nurse, oncology sister, or coordinator $6 / 55(11 \%) v 1 / 61(2 \%)$, unadjusted odds ratio $=0.14(0.2$ to $1 \cdot 17)$, combined $\chi^{2}=6.05, \mathrm{df}=1$, $p=0 \cdot 02$ ). There were no other significant differences between groups.

Bereaved carers in the two groups were equally likely to be satisfied with the place of death, both from their own and from the patient's perspective. There were no differences between groups in satisfaction with care and information received from hospitals, general practitioners, and district nurses (table VII), or in the proportion reporting that ordered equipment arrived when it was needed, that care was well coordinated, that everything was done for the patient that should have been done, that they knew how to get the help they needed for the patient, and that they had experienced no difficulty in contacting health professionals for help and advice when needed or in getting help in a night time emergency.

EXPERIENCE OF CARERS

Although 67 carers $(57 \%)$ said they were able to see friends and family as often as they wished, 40 carers $(34 \%)$ reported needing some time off from caring for the patient. Half the carers in employment had had to take time off work in the previous month to look after the patient and $59(50 \%)$ felt that caring was causing other problems for the family. Nevertheless, only 18 $(15 \%)$ said that the dissatisfaction of caring for the patient outweighed the satisfaction. There were no significant group differences.

On the Leeds depression scale 46 carers (39\%) had scores above 7 , the recommended cut off point for psychiatric morbidity; $54(46 \%)$ carers scored above the cut off point on the anxiety scale, and $54(46 \%)$ reported suffering from sleeplessness in the few days before interview. There were no significant differences between groups. Similarly, the two groups of carers did not differ significantly in the proportions scoring above the cut off points on the Leeds scales at the interview after bereavement (table IV). A total of 47 $(52 \%)$ bereaved carers were unable to stop thinking about the patient, $29(32 \%)$ found it difficult to accept his or her death, and seven ( $8 \%$ ) felt guilty when they thought about the patient. Coordination group carers were significantly less likely to feel angry when they thought of the patient's death (8/51 $v 15 / 40$, adjusted odds ratio $=3 \cdot 1 \quad(1 \cdot 15$ to $8 \cdot 3)$, combined $\chi^{2}=4 \cdot 08$, $\mathrm{df}=1, \mathrm{p}=0.04)$. There were no differences in the proportions of each group reporting excellent or good physical health, in the proportion feeling physically ill in some way, or in the proportion reporting that their health was at least as good as it was before the patient's death.

\section{Discussion}

Few differences were found in symptoms and symptom control, service provision and satisfaction, 
TABLE VII-Satisfaction of carers at interview after bereavement with place of death of subject and with aspects of care received by subject

\begin{tabular}{|c|c|c|c|c|c|}
\hline \multirow[t]{2}{*}{. } & \multicolumn{2}{|c|}{ No able to comment } & \multicolumn{2}{|c|}{$\begin{array}{l}\text { No (\%) agreeing } \\
\text { with statement }\end{array}$} & \multirow{2}{*}{$\begin{array}{c}\text { Adjusted odds ratio } \\
\text { (95\% confidence } \\
\text { interval) })^{\star} \\
\end{array}$} \\
\hline & $\begin{array}{l}\text { Study } \\
\text { group }\end{array}$ & $\begin{array}{l}\text { Control } \\
\text { group }\end{array}$ & $\begin{array}{l}\text { Study } \\
\text { group }\end{array}$ & $\begin{array}{l}\text { Control } \\
\text { group }\end{array}$ & \\
\hline \multicolumn{6}{|l|}{ Place of death right place: } \\
\hline For patient & 50 & 41 & $34(68)$ & $28(68)$ & $0.63(0.24$ to 1.64$)$ \\
\hline For carer & 51 & 41 & $39(77)$ & $32(78)$ & $0.63(0.23$ to 1.75$)$ \\
\hline $\begin{array}{l}\text { Hospital told carer all they wanted to know } \\
\text { during patient's final illness }\end{array}$ & 47 & 40 & $24(51)$ & $26(65)$ & $0.70(0.29$ to 1.72$)$ \\
\hline Satisfied with care from hospital & 45 & 39 & $23(51)$ & $19(49)$ & $1.12(0.46$ to 2.77$) \dagger$ \\
\hline \multicolumn{6}{|l|}{ GP told carer all they wanted to know } \\
\hline during patient's final illness & 40 & 32 & $24(60)$ & $18(56)$ & $1.19(0.46$ to 3.03$)$ \\
\hline Satisfied with care from GP & 41 & 32 & $30(73)$ & $22(69)$ & $1.45(0.52$ to 4.0$) \dagger$ \\
\hline Satisfied with care from nurses at home & 41 & 27 & $31(76)$ & $20(74)$ & $1.09(0.35$ to 3.33$) \dagger$ \\
\hline Ordered equipment arrived when needed & 39 & 29 & $19(49)$ & $17(59)$ & $0.69(0.26$ to 1.85$)$ \\
\hline Care was well coordinated & 50 & 39 & $31(62)$ & $27(69)$ & $0.62(0.24$ to 1.59$)$ \\
\hline $\begin{array}{l}\text { Had no difficulty contacting health } \\
\text { professionals when help or advice needed }\end{array}$ & 45 & 38 & $41(91)$ & $36(95)$ & $0.57(0.09$ to 3.33$) \dagger$ \\
\hline $\begin{array}{l}\text { Had no difficulty contacting health } \\
\text { professionals when help needed } \\
\text { during night }\end{array}$ & 27 & 13 & $21(78)$ & $13(100) \ddagger$ & \\
\hline $\begin{array}{l}\text { Everything done for patient that should } \\
\text { have been done }\end{array}$ & 51 & 39 & $30(59)$ & $23(59)$ & $0.97(0.41$ to 2.32$)$ \\
\hline $\begin{array}{l}\text { Carer knew how to get all help } \\
\text { needed for patient }\end{array}$ & 51 & 41 & $33(65)$ & $27(66)$ & $0.92(0.38$ to 2.22$)$ \\
\hline
\end{tabular}

*Adjusted for change in randomisation

tUnadjusted.

$\ddagger$ Odds ratio not calculated owing to small numbers in subgroups.

and social and psychological support between those patients and families who received the services of nurse coordinators in addition to routinely available services and those who received routine services only. The significant differences that were found are few enough to be ascribed to chance. Moreover, carers of patients in the coordination and control groups were equally likely to report that care had been well coordinated, and provision of services in the fortnight before interview did not differ between groups; thus it seems that the service made little, if any, difference to the coordination of care. The results suggest that the form of coordinating service used in this trial is not a useful addition to the range of services currently available for terminally ill patients.

Control group patients were more likely than coordination group patients to die before the end of the study and had a shorter median survival. As this effect was most pronounced during the period before the randomisation change it is not clear whether in its early months the coordinating service was having a measurable effect on survival or whether this result is an artefact resulting from, for instance, the large number of comparisons made. The failure of the coordinating service to have significant effects on other patient and family outcomes suggests the latter interpretation. It is important to note that, as scores on many of these variables would be expected to deteriorate as death approached, ${ }^{12}$ this finding would have enhanced the likelihood of detecting a beneficial effect of the coordinating service and cannot, therefore, account for the lack of significant effects of the coordinating service on outcomes.

\section{PROVISION OF SERVICES}

During the course of the trial, palliative care services in Wandsworth included a medical oncologist and attached multidisciplinary team, Macmillan nurses, and a hospice, in addition to standard hospital, primary care, community nursing, and social services. The coordinating service may have had little opportunity to improve care further given the comprehensive existing service provision for terminally ill patients. However, these results and others presented elsewhere ${ }^{18}$ show that some patients had unmet needs for medical, nursing, and social support and that some patients and their families were not satisfied with the care they received. This suggests that the failure of the coordinating service to improve care was not simply because a high standard of routinely available care left little or no room for further improvements.

The coordinators' ability to obtain services was entirely dependent on the traditional health service ethos of altruism and goodwill. This may have contributed to the lack of differences in outcome between the groups, as the trial was taking place during a time of major restrictions in financial resources and staff. Future attempts at providing coordinating services might consider whether, in an internal market, some degree of budgetary control is necessary if coordinators are to be able not only to assess need for services but also to obtain these services.

\section{ROLE OF COORDINATORS}

The coordinators were not intended to provide skilled counselling or to offer expert palliative care advice. However, to ensure the cooperation of other health professionals in the district, the coordinators were required to have recognised nursing skills and expertise in care of the dying. As a result they were attempting to provide a service, the aims and modus operandi of which ran contrary to their professional training and skills and to their motivation for working in the emotionally demanding field of care of the dying. Experience among those operating case management services for the elderly and psychiatric patients, which are closely allied to the coordinating service in approach and rationale,${ }^{19}$ has shown that skilled professionals are less suited to the "service broker" model of service reported in this paper than are relatively less skilled non-professionals, ${ }^{20}$ not least because case management activities tend to be neglected if the case manager has other professional skills to offer..$^{21} \mathrm{~A}$ mismatch between the professional skills of the nurse coordinators and the requirements of the coordinating role may have contributed to the inadequacies of this service.

In conclusion, the Wandsworth coordinating service for terminally ill cancer patients failed to produce either better service coordination or improved patient or family outcomes. Nevertheless, service coordination or case management may have much to offer terminal care: the groups traditionally offered these services present similar challenges to those seeking to provide efficient and coordinated services in that the care of these patients is shared between primary care, the hospital sector, and voluntary organisations. Those considering establishing such services should consider whether the service might have some degree of budgetary control and, in particular, what skills and background are most appropriate for this role.

We thank the patients and families who participated in this research and our interviewers, J Ochera, E Rink, and J Taylor. We thank Wandsworth Health Authority for providing the nurse coordinators, and in particular Drs T Gould, D Hennessy, and E Vincent for their help. We are grateful to the many consultants who supported this work, in particular Professor RC Coombes and Dr G Griffin, and Dr $\mathrm{E} D$ Tod and the many other doctors and nurses who collaborated in this study. We thank the anonymous reviewers for their helpful comments. This research was supported by the Medical Research Council.

1 Hockley JM, Dunlop R, Davies RJ. Survey of distressing symptoms in dying patients and their families in hospital and the response to a symptom control team. BMF 1988;296:1715-7.

2 Houts PS, Yasko JM, Harvey HA, Kahn SB, Hartz AJ, Hermann JF, et al. Unmet needs of persons with cancer in Pennsylvania during the period of terminal care. Cancer 1988;62:627-34.

3 Higginson I, Wade A, McCarthy M. Palliative care: views of patients and their families. $B M 7$ 1990;301:277-80

4 Cartwright A, Hockey L, Anderson JL. Life before death. London: Routledge and Kegan Paul, 1973

5 Wilkes E. Dying now Lancet 1984;i:950-2.

6 Lunt B, Hillier R. Terminal care: present services and future priorities. BMJ 1981;283:595-8.

7 Seale CF. What happens in hospices: a review of research evidence. Seale CF. What happens
Soc Sci Med 1989;28:551-9.

8 Kane RL, Bernstein L, Wales J, Bernstein L, Leibowtz A, Leaplan S. A randomised controlled trial of hospice care. Lancet 1984;i:890-4. 
9 Directory of hospice services: Sydenham: St Christopher's Hospice Information Service, 1992

10 Wilkes E. Terminal care: report of a working party of the Standing Medical Advisory Committee. London: HMSO, 1980. .

11 Spitzer WO, Dobson AI Hall J, Chamberlain E, Levi J, Shepherd $\mathrm{R}$ et al. Measuring the quality of life of cancer patients: a concise QL-index for use Measuring the quality of life of cancer patient

12 Morris JN, Sherwood S. Quality of life of cancer patients at different stages in their disease trajectory. I Chronic Dis 1987;40:545-53.

13 Zigmond AS, Snaith RP. The hospital anxiety and depression scale. Acta Psychiatr Scand 1983;67:361-70.

14 Smilkstein G, Ashworth C, Montano D. Validity and reliability of the Family APGAR as a test of family function. $\mathcal{F}$ Fam Prac 1982;15:303-1 1

15 Snaith RP, Bridge GWK, Hamilton M. The Leeds scale for the self-assessment of anxiety and depression. Br f Psychiatry 1976;128:156-65.
16 Armitage P, Berry G. Statistical methods in medical research. Oxford: Blackwell Scientific, 1987

Altman D. Practical statistics for medical research. London: Chapman and Hall, 1991.

18 Addington-Hall JM, MacDonald LD, Anderson HR, Freeling P. Dying from cancer: the views of bereaved family and friends about the experiences of cerminally ill patients. Palliative Medicine 1991:5:207-14.

9 Shepherd G. Case management. Health Trends 1990;22:59-61.

20 Hurley RE. Towards a behaviourial model of the physician as case manager. Soc Sci Med 1986;23:82.

1 Rapp CA, Chamberlain R. Case management services for the chronically mentally ill. Social Work 1985;3:417-22.

(Accepted 3 September 1992)

\title{
National survey of current arrangements for diversion from custody in England and Wales
}

\author{
S Blumenthal, S Wessely
}

\begin{abstract}
Objectives-To assess the extent and nature of psychiatric assessment schemes based at magistrates' courts in England and Wales for the early diversion of mentally disordered offenders from custody and to determine the response of the NHS to new initiatives concerning alternatives to custody for this group.
\end{abstract}

Design-Postal survey of the probation service, petty sessional divisions, mental health provider units, and district purchasing authorities in England and Wales.

Subjects-All chief probation officers $(n=55)$, clerks to the justices $(n=284)$, managers of mental health provider units $(n=190)$, and purchasers of mental health services $(n=190)$ in each of the district health authorities.

Main outcome measures-Number of psychiatric assessment schemes, practical difficulties in their operation, extent of regular liaison with health and social services; current and future intentions to purchase or provide services for diversion from custody.

Results-Data were obtained from every magistrates' court. Forty eight psychiatric assessment schemes were identified with another 34 under development. Particular problems were lack of adequate transport arrangements, difficulties with hospital admissions, and overdependence on key people. There was little liaison between health, social services, and members of the criminal justice system. Twenty five of the 106 purchasers who responded had a policy dealing with diversion, and 39 had a scheme under development; 56 purchasers had no current or future plans about diversion. Sixty nine of the 150 providers who responded reported that diversion was included in their current or next business plan.

Conclusion-Schemes to divert mentally disordered offenders from the criminal justice system are often hampered by lack of adequate transport arrangements, difficulties in hospital admissions, and overdependence on key people.

Psychological Medicine

King's College Hospital

School of Medicine and

Institute of Psychiatry,

London SE5 9RS

S Blumenthal, research

worker

$\mathrm{S}$ Wessely, senior lecturer

Correspondence to:

Dr Wessely.

BMF 1992;305:1322-5

\section{Introduction}

Increasing attention is being paid to the problems of mentally abnormal offenders and the need to provide appropriate alternatives to custody, or "diversion." There is general dissatisfaction with the current system in which mentally ill people are often remanded in custody for medical reports despite widespread recognition of the inappropriateness of these arrangements.
At present once a mentally disordered offender is remanded in custody there are typically delays between requesting an assessment, receiving assessment, and hospital admission. ${ }^{2}$ Current arrangements for mentally abnormal offenders were recognised as unsatisfactory in a recent Home Office circular (66/90) which stated that "a mentally disordered person should never be remanded to prison simply to receive medical treatment or assessment" and concluded that "it is government policy that, wherever possible, mentally disordered persons should receive care and treatment from the health and social services." ${ }_{3}$ The Reed committee has recently begun to consider methods of developing and improving psychiatric services for mentally disordered offenders. ${ }^{4}$ One aspect of our review is an appraisal of present arrangements for the early diversion of mentally disordered offenders from the criminal justice system.

The Reed committee identifies a joint responsibility of the Home Office and the Departments of Health and Social Services to ensure the early diversion and improved management of mentally disordered offenders. ${ }^{34}$ The aim of diversion is to reduce the role of the criminal justice system and increase that of the health service. In response liaison schemes providing a psychiatric assessment service at magistrates' courts have appeared in various parts of the country. These schemes have not been surveyed systematically and there is no information about local variations in the coverage of, and need for, such facilities. There is also no information on how regional and district health authorities have responded to the Home Office's circular $66 / 90$ and the recommendations of the Reed committee. It is unclear how the new NHS structures have affected services for mentally disordered offenders and what roles purchasers and providers perceive themselves to fulfil.

We report a comprehensive survey of the extent of diversion schemes in England and Wales and the way in which new health service structures have responded to current directives to improve psychiatric services to mentally disordered offenders.

\section{Methods} officers in each of the probation areas $(n=55)$, the clerks to the justices responsible for each of the petty sessional divisions $(n=284)$, and the purchasers $(n=190)$ and providers $(n=190)$ with responsibility for mental health services in each of the district health authorities in England and Wales.

The questionnaire to the probation officers and
A postal survey was undertaken of chief probation 